
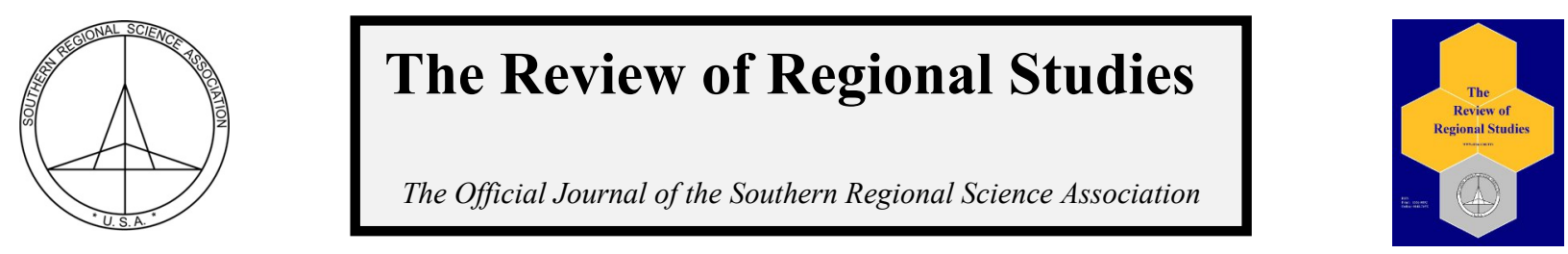

\title{
Racially Polarized Voting in a Southern U.S. Election: How Urbanization and Residential Segregation Shape Voting Patterns*
}

\author{
Russell Weaver ${ }^{\mathrm{a}}$ and Sharmistha Bagchi-Sen ${ }^{\mathrm{b}}$ \\ ${ }^{a}$ Department of Geography, Texas State University, USA \\ ${ }^{b}$ Department of Geography, University at Buffalo, SUNY, USA
}

\begin{abstract}
This paper advances a model of racially polarized voting that captures the intervening effects of urbanization and residential segregation on white voters' political behavior. The model is tested for a 2011 referendum election in the U.S. state of Mississippi. Using King's method of ecological inference and weighted least squares regression, we find that regional minority population size impacts white opposition to minority-preferred political alternatives both directly and indirectly through an effect on residential racial segregation. Importantly, these influences hinge on intra-regional patterns of urbanization. The findings have important implications for understanding spatial variation in regional political behavior and intergroup relations.
\end{abstract}

Keywords: regional political behavior, race, polarization, urban, segregation, southern politics

JEL Codes: D72, Z18

\section{INTRODUCTION}

Racially polarized voting outcomes in the United States attract ample attention from academic researchers, journalists, and legal scholars (McCrary, 1990; Voss, 2000; Orey, 1998, 2001; Tolbert and Grummel, 2003; Roch and Rushton, 2008; Donovan, 2010; Webster and Quinton, 2010; Cohen and Helderman, 2012). Among the reasons for this high level of interest is that such outcomes have historically been interpreted as signals of underlying intra-regional tensions among racial groups (Key, 1949; Blalock, 1967), and, often, as manifestations of the non-Hispanic white (hereafter "white") majority's "hostility" toward minorities (Giles, 1977; Giles and Buckner, 1993). The latter of these propositions is traceable to Key's (1949) classic explorations of post-World War II election outcomes in the American South. Key finds evidence to support what has come to be called a "racial threat" hypothesis in southern voting patterns, whereby white voters vote predominantly against ballot choices that seem to favor minority interests (Rocha and Espino, 2009; Orey et al., 2011). The mechanism theorized to drive this process relates to the size of the minority population in the observed geographic unit: as the density of minority persons in a given space rises, white opposition to the preferred ballot choices of minority voters intensifies (Giles and Buckner, 1993; Orey, 1998, 2001). This effect is perceived to be a protective measure, in that whites supposedly identify decreases in their relative share of total areal population as threats to their collective economic and political power (Karahan and Shughart, 2004).

\footnotetext{
* The authors thank Co-editor Michael Lahr and two anonymous reviewers for their valuable feedback and suggestions.

Weaver is Assistant Professor of Geography at Texas State University, San Marcos, TX, 78666. Bagchi-Sen is Professor and Chair of Geography at the University at Buffalo, NY, 14261. Corresponding Author: R. Weaver E-mail: rcweaver@txstate.edu
}

(c) Southern Regional Science Association 2015.

ISSN 1553-0892, 0048-749X (online)

www.srsa.org/rrs 
Although originally applied to the South, this effect has been ascribed to the broader context of all American elections (Huckfeldt and Sprague, 1993; Tolbert and Grummel, 2003; Donovan, 2010). Indeed, since its introduction, the racial threat hypothesis has received substantial support in the literature (Blalock, 1967; Giles, 1977; Giles and Buckner, 1993), including from many contemporary studies (Tolbert and Grummel, 2003; Donovan, 2010; Orey et al., 2011). Critical examinations (e.g., Voss, 2000) point out that much of this work oversimplifies the geographic properties of polarized voting patterns, however. Some researchers note that the underlying relationship between white majority opposition to minority preferred ballot alternatives and minority population density is likely moderated by local urbanization patterns (Voss, 1996, 2000; Orey, 1998, 2001; Tolbert and Grummel, 2003). When this moderated relationship is explicitly accounted for in quantitative analyses, it has been found that higher minority population shares in fact enhance white support for minority preferred alternatives (Voss, 2000; Voss and Miller, 2001). The explanation for this result is that, as the minority share of the regional population increases, more of the white majority interacts with minority persons, resulting in improved majority-minority relations (Liu, 2001; Oliver and Wong, 2003). This "social contact" hypothesis therefore contradicts the racial threat thesis (Hood and Morris, 2000).

Among other reasons, because this moderated relationship represents a more sophisticated treatment of geographic space relative to racial threat studies, some researchers (e.g., Voss, 2000; Voss and Miller, 2001) suggest that the threat hypothesis is outdated and no longer describes observable, real-world conditions. Taking issue with this assertion, some subsequent studies that employ similar to or even more sophisticated analytical techniques than those used by social contact proponents, find that not only does the racial threat thesis still apply, but urbanization can compound (as opposed to mitigate) its effects (Orey et al., 2011). Thus, the literature continues to bear an apparent contradiction with respect to racially polarized voting outcomes.

The present study engages with this contradiction by adding another spatial consideration to the relationship. Explicitly, as Rocha and Espino (2009, 2010) observe, measures of relative minority population size alone are ill-equipped to capture the relative propensities for intergroup interactions to lead to hostile (racial threat) or ameliorative (social contact) voting outcomes. This is because such measures report little about the degree to which mutually exclusive racial groups might interact within residential geographies. From this viewpoint, it seems logical that residential racial segregation might play a significant role in polarized voting outcomes (Roch and Rushton, 2008; Rocha and Espino, 2009, 2010).

It is in this research context that we examine the multifaceted relationship between racial composition and majority white voting behavior. Importantly, we introduce residential segregation as a mediator into the established relationship between urbanization, minority population size, and white support for minority-preferred political alternatives. We examine this relationship for a 2011 racially polarized referendum election in the State of Mississippi. The referendum provided citizens with an opportunity to enact a new voter identification (ID) law in Mississippi that would require voters to show unexpired photographic ID to poll workers prior to receiving a ballot. Such measures are claimed to be racially polarizing, insofar as minorities tend to possess acceptable forms of photo ID at lower rates than whites (NAACP, 2011). Overall, this study's focus on the interactions between regional urbanization and residential segregation represents a new contribution to the inchoate body of empirical research on segregation and vote 
polarization. The results strongly suggest that neither racial threat nor social contact comprehensively explains polarized election returns; rather, both mechanisms are operating across regions, but in different sociospatial contexts.

\section{RACIAL THREAT AND SOCIAL CONTACT IN REGIONAL POLITICS}

Polarized voting outcomes certainly are not unique to the U.S. (Lublin and Voss, 2002). Still, most literature and research on the topic is on American elections and observations or analyses thereof (Key, 1949; Blalock, 1967; McCrary, 1990; Giles and Buckner, 1993; Forbes, 1997; Voss, 1996, 2000; Orey, 1998, 2001; Voss and Miller, 2001; Tolbert and Grummel, 2003; Rocha and Espino, 2009; Donovan, 2010; Orey et al., 2011). Accordingly, we rely on the relevant American literature to frame our research.

Returning to Key's (1949) seminal work on the American South, a strict interpretation of what is now called the "racial threat" hypothesis is that increases to the relative minority population size in a given area incite anti-minority political sentiments in the white majority, regardless of other features of a region's socioeconomic and cultural environment (Donovan, 2010). Key (1949) supports this assertion by finding that minority preferred candidates in primary or general elections for office tend to receive significantly less support from white voters in counties with relatively high minority populations, compared to counties where the minority population is insubstantial. A large collection of subsequent studies reinforce the underpinnings and implications of this thesis using contemporary statistical techniques to analyze both historical (Giles and Buckner, 1993) and recent elections (Tolbert and Grummel, 2003; Karahan and Shughart, 2004; Donovan, 2010; Orey et al., 2011). Indeed, it has been claimed that white majority "hostility" toward racial minorities, and the notion that it "varies as a direct function of [minority] presence in the population," is a mainstay of American politics (Huckfeldt and Sprague, 1993, p. 284 [as quoted by Orey, 1998]).

Notwithstanding the accumulated empirical evidence for the racial threat hypothesis (Giles and Buckner, 1993; Huckfeldt and Sprague, 1993; Tolbert and Grummel, 2003; Karahan and Shughart, 2004; Donovan, 2010; Orey et al., 2011), several scholars object to the idea that a sufficient number of contemporary white voters in America exhibit racist tendencies (Liu, 2001; Voss, 1996, 2000; Voss and Miller, 2001; Roch and Rushton, 2008) to enable such robust, widespread results. They, instead, claim that the evidence uncovered to support the racial threat thesis is strictly an artifact of pre-existing "old fashioned racism" in the American South, and that polarized voting outcomes - whether in or out of the South - are now more likely to be explained by nonracial factors such as cultural backlash (Voss, 1996, 2000) or regional socioeconomic conditions (Oliver and Mendelberg, 2000; see also the literature review in Tolbert and Grummel, 2003). Taking this argument a step further, opponents of the racial threat hypothesis assert that, in direct contraposition to Key's (1949) influential thesis, increases to the minority population share of a given geographic territory lessen white hostility toward rival racial groups (Hood and Morris, 2000; Liu, 2001; Voss and Miller, 2001; Oliver and Wong, 2003). This claim is the cornerstone of the so-called "social contact" hypothesis introduced earlier in this paper, which implies that a large minority presence in a region can bring about white majority support for minority-preferred alternatives in elections (Forbes, 1997; Liu, 2001; Rocha and Espino, 2009).

As with tests of racial threat (e.g., Giles and Buckner, 1993), empirical investigations of the social contact hypothesis regularly model white support for alternatives specifically not 
preferred by minorities as a function of a region's minority population's relative size in addition to a number of controls (Liu, 2001; Voss and Miller, 2001). Unlike many early racial threat studies, though, social contact proponents frequently consider the relative size of the minority population in tandem with regional patterns of urbanization (Voss, 1996, 2000). This contributes significantly to the conceptualization of space in polarized voting outcomes. Specifically, the social contact hypothesis suggests that the relationship between the relative size of the minority population and white majority opposition to minority preferred alternatives is moderated by urbanization (Voss, 2000). With this insight, some (e.g., Voss, 2000) argue that the relationship that Key (1949) originally articulated to explain racially polarized voting patterns omits an essential attribute of the underlying political geography.

Consequently, social contact proponents argue that what has been called the "sociocultural law" of white majority hostility towards minorities in public elections requires critical reexamination in more well-defined geographical contexts (Voss and Miller, 2001). Attending to this concern, Voss and his colleagues reevaluate polarized voting outcomes in the American South-where the racial threat hypothesis has its origins - in the construct of the moderated relationship described above (Voss, 1996, 2000; Voss and Miller, 2001). These studies find that, both in past elections where racial threat had previously been found to apply (Voss, 1996, 2000; Giles and Buckner, 1993), and in more recent racially charged elections (Voss and Miller, 2001), white majority hostility toward minorities tends to be reversed in urban areas and weakens elsewhere when the relationship is expanded to include the geographic character of the rural-urban continuum. Such findings are used by Voss and Miller (2001, p. 73) to claim that white hostility "does not characterize contemporary voting on racial issues, even when the method and the data resemble those upon which [racial threat] was originally built".

Responding critically to this conclusion, some racial threat proponents (Orey, 2001; Orey et al., 2011) have refocused their attention on the American South, finding that the moderated relationship specified by social contact proponents can and does still reveal a strong racial threat effect in southern elections. Given these and related findings from outside of the South (Tolbert and Grummel, 2003; Rocha and Espino, 2009; Donovan, 2010), the book cannot be closed on the racial threat-social contact debate. The issue seems to have unwound into a matter researcher pre-conceptions. Indeed, the disparate hypotheses both continue to enjoy empirical support, even when quantitative testing is carried out in highly similar manners and for elections in the same geographic regions (Voss and Miller, 2001; Orey et al., 2011).

Attending to this observation, we draw on recent studies that examine the impact of residential segregation on polarization to inform our own empirical tests. In particular, Rocha and Espino (2009) find that racial threat and social contact perspectives shape majority white political attitudes in a given region depending on demographic spatial organization. Stated differently, the degree to which racial groups are segregated in residential space intervenes to make one or the other of the two hypotheses more or less apt for explaining polarized electoral outcomes (Rocha and Espino, 2009). The ability of racial threat or social contact to explain racial vote polarization is therefore conditional, not absolute.

Thus, just as social contact proponents point out (e.g., Voss, 2000) that relative minority population size is on its own insufficient to explain racial vote polarization, Rocha and Espino (2009) observe that neither urbanization nor relative minority population size are adequate indicators of the degree to which multiple racial groups share common residential spaces. Note, though, that scholars from both sides of the theoretical aisle (Voss and Miller, 2001; Orey, 2001; 
Orey et al., 2011) tend to agree that polarization does operate differently in urban and rural regions. In this sense, we propose a conceptual model of racial vote polarization that introduces segregation as a mediator into the accepted relationship between urbanization, relative minority population size, and white majority support for non-minority preferred alternatives (Voss, 1996, 2000; Voss and Miller, 2001; Tolbert and Grummel, 2003; Orey et al., 2011). Such a model allows for both racial threat and social contact effects to manifest during the same election and in the same region, though in different intra-regional demographic settings.

In order to communicate this conceptual model most effectively, we first introduce the study context in which it is applied. Because both racial threat and social contact proponents acknowledge that ballot initiative elections dealing with racial policy issues potentially capture white political sentiments better than contests for public office (Voss and Miller, 2001; Tolbert and Grummel, 2003; Roch and Rushton, 2008; Orey et al., 2011), we choose to study a recent referendum election in the State of Mississippi. The decision to focus on Mississippi follows the numerous examples of recent studies that set out to challenge or expand on Key's (1949) original hypothesis by re-examining the applicability of racial threat in the geographic region-the American South - in which it was first formulated (Voss, 1996, 2000; Orey, 1998, 2001; Liu, 2001; Voss and Miller, 2001; Karahan and Shughart, 2004; Roch and Rushton, 2008; Orey et al., 2011).

\section{STUDY CONTEXT: 2011 MISSISSIPPI VOTER IDENTIFICATION REFERENDUM}

On November 8, 2011, Mississippi voters passed a ballot measure authorizing the state to enact a voter identification (voter ID) policy considered to be in the "most restrictive" category on a policy scale developed by Alvarez et al. (2007). The ballot measure-Initiative 27-calls on the state to constitutionally require potential voters to produce unexpired, valid photo identification prior to participating in an election. In general, such laws are intended to prevent voter fraud (Barreto et al., 2009; Alvarez et al., 2007; Alth, 2008; Hood and Bullock, 2008). But little evidence suggests that fraud is a systemic problem in American elections (Minnite, 2007). Thus, the issue has become highly controversial in the U.S. policy discourse (Alth, 2008; Davidson, 2009; NAACP, 2011). Regardless of the reasons or motivations for voter ID laws, a critical national debate has emerged surrounding the notion that these comparatively strict voting rules might disproportionately impact minority voters relative to whites (Alth, 2008; Barreto et al., 2009; NAACP, 2011). Both known data from federal voting rights cases and scholarly empirical research strongly suggest that minority voters lack acceptable forms of photo identification at much higher rates than whites (Hood and Bullock, 2008; Barreto et al., 2009; Texas v. Holder, 2012). Such claims entered into the public discourse well in advance of the Initiative 27 election, and they continue to receive popular attention (Berry, 2011; NAACP, 2011). Accordingly, the Mississippi voter ID referendum is expected to exhibit significant racial polarization.

Unlike similar policies in other states, the Mississippi case is unique in that Initiative 27 passed as a result of direct, not representative, democracy. ${ }^{1}$ That is to say, the rule change gained a ballot position via citizen petition, where it was then voted on by eligible participants in the

\footnotetext{
${ }^{1}$ In 2004 Arizona voters passed a voter ID law during a statewide referendum election. However, the law (1) did not mandate photo ID to vote and (2) was passed as part of a broader ballot question that was not concerned solely with voter ID. Oklahoma voters passed a voter ID policy as part of State Question 746 in 2010, though the increased racial variation in Mississippi relative to Oklahoma makes the former more suitable for our analysis.
}

(C) Southern Regional Science Association 2015. 
Figure 1: Geographic Distribution of Precincts Where Initiative 27 Was Rejected (Left); and Where Minority Persons Constitute a Majority of VAP (Right)

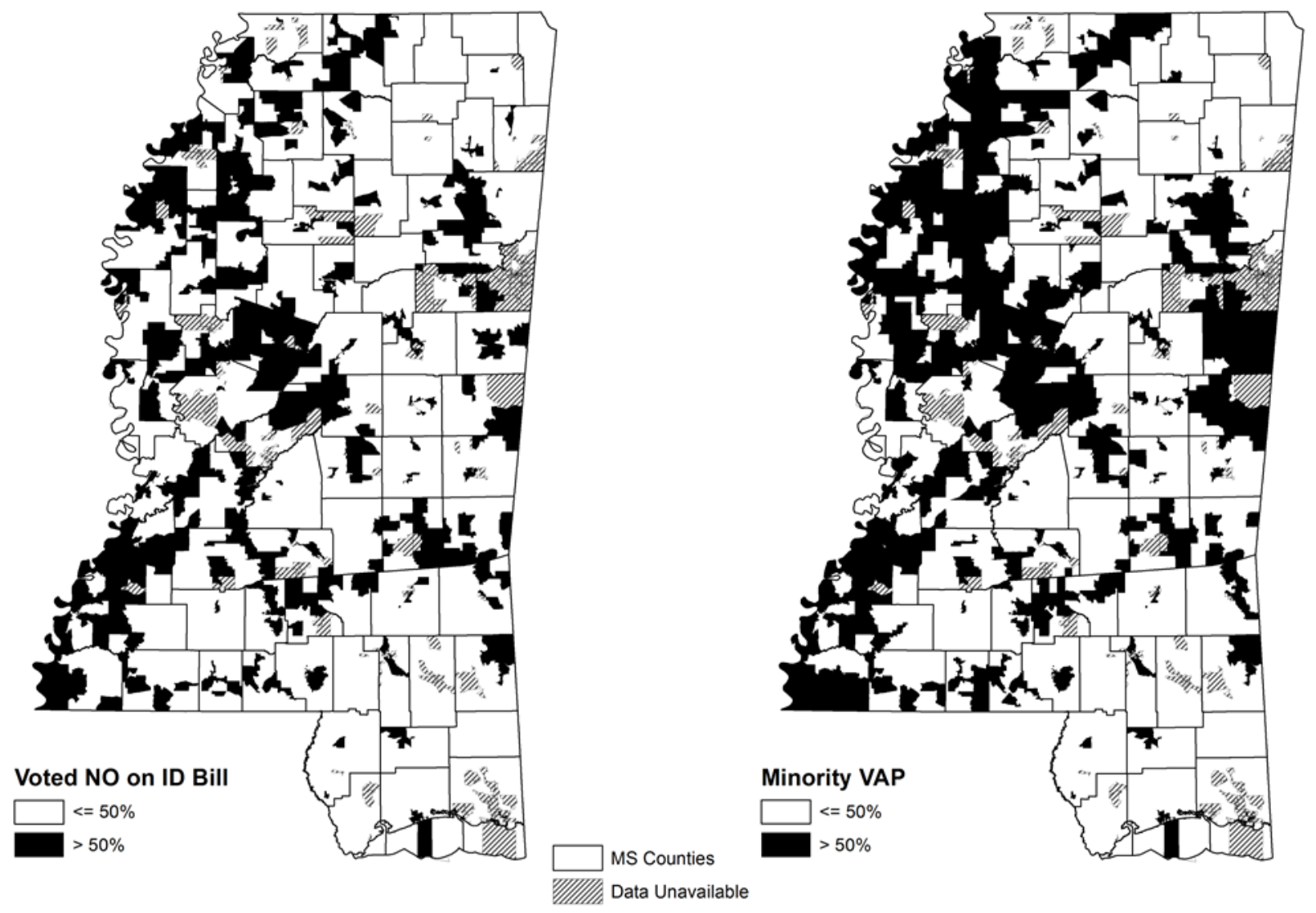

State of Mississippi. This makes Initiative 27 conveniently suited for our analysis (Tolbert and Grummel, 2003; Orey et al., 2011). Moreover, by popular vote the ballot measure passed with a 62 percent to 38 percent margin and, supporting the expectation articulated above, exploratory analyses suggest that these results were highly racially polarized (Table 1; Figure 1). For instance, a visual inspection of precinct-level demographic characteristics and Initiative 27 election returns (Fig. 1) shows that the spatial pattern of "NO" votes on the voter ID bill roughly follow the geographic distribution of Mississippi's minority voting-age population (VAP). The precincts in which the voter ID bill was rejected (i.e., received less than 50 percent +1 vote) are overwhelmingly those for which the majority VAP is nonwhite (Fig. 1). This relationship is explicitly quantified in Table 1, which makes it relatively clear that the Mississippi voter ID referendum election is consistent with racially polarized election results. While this observation is not necessarily surprising given the well-documented history of racially polarized politics in Mississippi (Key, 1949; Blalock, 1967; McCrary, 1990; Shaffer et al., 2000; Bleacher, 2001; Karahan and Shughart, 2004; Orey et al., 2011), it is of key significance here, to the extent that voter ID measures are often portrayed as being relatively racially blind and supported by a crosssection of society (Pew Research Center, 2012). Hence, we see clear signs of racial polarization on this ballot initiative that goes against both popular perceptions of voter-polling results as well as politically charged arguments that all citizens, regardless of demographic or socioeconomic characteristics, support voter ID policies (Pew Research Center, 2012; Fund and von Spakovsky, 2013).

(C) Southern Regional Science Association 2015. 
Table 1: Precinct Election Returns by Racial Population

\begin{tabular}{lccc}
\hline \hline & $\begin{array}{c}\text { YES Vote on } \\
\text { Voter ID }>50 \%\end{array}$ & $\begin{array}{c}\text { NO Vote on } \\
\text { Voter ID } \geq 50 \%\end{array}$ & $\begin{array}{c}\text { Total } \\
(\mathrm{n})\end{array}$ \\
\hline White VAP $>50 \%$ & $97.8 \%$ & $2.2 \%$ & 1,167 \\
Minority VAP $>50 \%$ & $19.3 \%$ & $80.7 \%$ & 566 \\
All Sample Precincts & $72.1 \%$ & $27.9 \%$ & 1,733 \\
\hline \hline
\end{tabular}

\section{CONCEPTUAL MODEL}

To this point, we have argued that the contemporary literature on racial vote polarization is moving toward a consensus that the relationship originally studied by Key (1949) — between regional minority population density and majority white support for nonminority preferred alternatives - is affected by the level of regional urbanization (e.g., Voss and Miller, 2001; Tolbert and Grummel, 2003; Orey et al., 2011). At the same time, however, polarization scholars have largely overlooked the role of geographic racial segregation in this relationship (Roch and Rushton, 2008; Rocha and Espino, 2009). This is the case despite the observation that segregation affects the potential for "social contact" between racial groups, which, in turn, can significantly influence white policy attitudes (Sigelman and Welch, 1993; Stein et al., 2000).

Recent work directed at this gap fittingly introduces segregation into Key's (1949) functional relationship - though it does so by either supplanting the urban-rural dimension of regional context (Rocha and Espino, 2009) or by treating segregation and urbanization as operating independently on majority white support for nonminority preferred alternatives (Roch and Rushton, 2008). We propose a different path forward (Figure 2). Namely, we hypothesize that minority population size and white support for (in our case) the Mississippi voter ID policy exist in a "moderated-mediated" relationship (Muller et al., 2005; Jaccard and Jacoby, 2010), whereby: (1) minority population has both a direct effect on majority white support and indirect effects through segregation, such that (2) both the direct and indirect effects are moderated by the level of urbanization in the areal unit of observation. That is, urbanization not only affects Key's (1949) original relationship, as has been established by, e.g, Voss (1996, 2000) and Orey (1998, 2001), but it also moderates indirect effects of minority population on majority white "hostility" via racial residential segregation. Hence, we extend an existing conceptual model with an erstwhile omitted element that is known to have substantive influences on racially polarized voting outcomes (Roch and Rushton, 2008; Rocha and Espino, 2009).

Regarding the geographic unit of analysis in Figure 2, polarization studies tend to use U.S. counties (Giles and Buckner, 1993; Orey, 1998, 2001; Voss and Miller, 2001; Karahan and Shughard, 2004; Roch and Rushton, 2008; Orey et al., 2011) or metropolitan areas (Rocha and Espino, 2009, 2010) to describe geographic characteristics. In contrast, we support the claim that comparatively disaggregated voting precincts are better suited for capturing potential intergroup residential interactions and, by extension, "neighborhood" level dynamics (Carsey, 1995; Liu, 2001; see also Tolbert and Grummel, 2003). Furthermore, in the context of Baybeck's (2006) findings that multiple spatial milieus influence racial voting patterns, our model is designed to control for unobserved county-level fixed effects, as will be expanded on below. 
Figure 2: Conceptual Model of White Support for Initiative 27

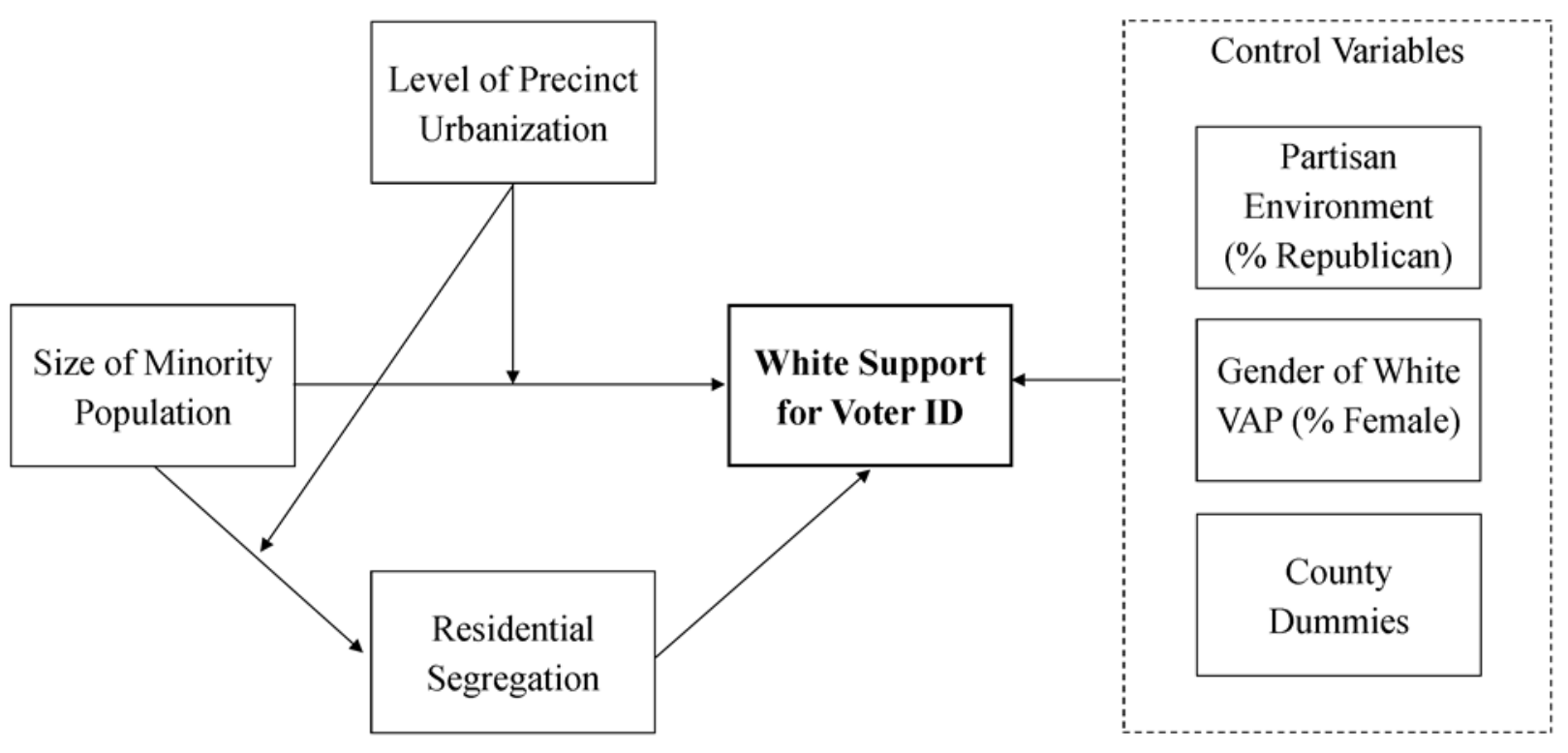

\section{DATA}

The data for our analysis come from four sources (Table 2). First, all (known) precinctlevel election data were acquired from the Mississippi Secretary of State (MS SOS) Division of Elections. ${ }^{2}$ Second, precinct population and voting-age population (VAP) data, by race, come from the 2010 Census redistricting summary file by way of the Mississippi Automated Resource Information System (MARIS) state website. ${ }^{3}$ Geographic precinct boundaries and precinct names were also acquired through MARIS. Third, supplemental decennial U.S. Census data were downloaded directly from the 2010 Census Summary File 1 (SF1) to quantify the Censusdesignated "urban" and "rural" populations for each voting precinct. Finally, critical information on voter turnout and support for the voter ID policy, by race, were estimated using King's (1997) method of ecological inference (EI). Due to insufficient reporting by some counties, and the need to omit precincts that do not simultaneously exist in both the MARIS precinct boundary database and the MS SOS 2011 election returns, our sample consists of 1,733 (88 percent) of all voting precincts listed in the MARIS database (Fig. 1).

\subsection{Dependent Variable}

In order to test for the moderated-mediated relationship depicted in Figure 2, it is necessary to know the level of white support for the voter ID policy in each Mississippi voting precinct (i.e., the dependent variable). Of course, as polarization scholars are well aware, it is typically the case that such information is unobservable due to lack of state data collection on the racial characteristics of voters (Roch and Rushton, 2008). To overcome this issue, we follow the expansive body of polarization research that employs King's (1997) method of ecological inference $(\mathrm{EI})$ to derive estimates and standard errors for our dependent variable.

\footnotetext{
${ }^{2}$ See http://www.sos.ms.gov/elections.aspx

${ }^{3}$ See http://www.maris.state.ms.us/HTM/Data.html

${ }^{4}$ Census 2010 SF1, Table P2 was queried to obtain values for "total", "urban", and "rural" populations by census block. Source: http://www2.census.gov/census_2010/04-Summary_File_1/Mississippi/
}

(C) Southern Regional Science Association 2015. 
For our analysis, King's EI entails first estimating voter turnout by race, by drawing on known precinct-level data for the (1) size of precinct voting-age population (VAP), (2) percentage of VAP that voted in the voter ID referendum, and (3) racial breakdown of precinct VAP. More precisely, turnout estimates are first constrained by deterministic (feasible) bounds based on the observed data. Next, all feasible turnout values for each precinct are analyzed in the context of maximum likelihood to derive point estimates and standard errors for precinct-level racial group turnout. Those turnout results are then used to generate "step two" estimates of white support for voter ID, by estimating a second-level King's EI equation in much the same way as above (King, 1997; Roch and Rushton, 2008). The global estimates obtained from this process are included alongside descriptive statistics for the remainder of our data in Table 2. Confirming our expectation of racially polarized voting outcomes, which were developed during exploratory analyses earlier in the article (Table 1; Fig. 1), the EI estimates reveal that approximately 82 percent of white voters supported the voter ID policy, compared to an estimated 22 percent of minority voters (Table 2 ).

\subsection{Explanatory Variables}

Referring to the conceptual model of racial vote polarization in Figure 2, our analysis of the 2011 Mississippi voter ID referendum features three focal explanatory variables and a number of controls. Given that this research is motivated by the contradictory results produced by separate evaluations of the moderated relationship between urbanization, minority population size, and white support for non-minority preferred alternatives (Voss and Miller, 2001; Orey et al., 2011), and our interest in introducing residential racial segregation into this equation, our focal predictors describe geographic properties of Mississippi voting precincts. First, census block-level data for total population and VAP are spatially aggregated to state voting precinct boundaries, so that population and VAP can be broken down by race for each observational unit (note that Census blocks are wholly contained by precincts, meaning that no interpolation is involved when aggregating block-level data to voting precincts). Second, Census block-level population data from the 2010 Census SF1 (Table P2)—which separates the total block population into "urban" and "rural" categories - are aggregated to precinct boundaries to compute the urbanized share of each precinct's population. ${ }^{5}$ Third, for each precinct we use Census block-level data on total white population and total non-white population to compute a measure of segregation, the index of dissimilarity $(D)$, which reports the proportion of the population that would have to move to a different Census block in order for all blocks to have the same racial makeup as the given precinct (Massey and Denton, 1988). $D$ is the metric of segregation employed by Roch and Rushton (2008) and Rocha and Espino $(2009,2010)$ in their research on racial vote polarization. We follow their example. $D$ is calculated for each precinct as:

$$
D_{i}=0.5 \cdot \sum_{j=1}^{k}\left|\frac{\text { White }_{j}}{\text { White }_{T}}-\frac{\text { NonWhite }_{j}}{\text { NonWhite }_{T}}\right|
$$

where, $D_{i}$ is the dissimilarity index for precinct $i$, each precinct $i$ contains $k$ census blocks such that $j=\{1,2, \ldots, k\}$, White $_{j}$ is the white population in census block $j$, White $e_{T}$ is the total white

\footnotetext{
${ }^{5}$ See footnote $\# 4$ above.
}

(C) Southern Regional Science Association 2015. 
Table 2: Characteristics of Sample Precincts

\begin{tabular}{lccc}
\hline \hline Variable & Mean & Std. Dev. & Source \\
\hline Precinct Total Population & 1,552 & 1,393 & MS MARIS \\
\% Minority & 0.401 & 0.300 & MS MARIS \\
Precinct Voting Age Population (VAP) & 1,155 & 1,035 & MS MARIS \\
\% Minority & 0.381 & 0.295 & MS MARIS \\
Votes Cast in ID Referendum & 457 & 373 & MS SOS \\
\% Yes & 0.603 & 0.191 & MS SOS \\
Overall Turnout (\% of Total VAP) & 0.438 & 0.135 & [Votes Cast / VAP] \\
White Turnout (\% of White VAP) & 0.427 & 0.002 & King's EI \\
Minority Turnout (\% of Minority VAP) & 0.344 & 0.003 & King's EI \\
\% White Support for Voter ID* & 0.816 & 0.001 & King's EI \\
\% Minority Support for Voter ID & 0.220 & 0.003 & King's EI \\
Precinct \% Urbanized & 0.294 & 0.415 & 2010 Census \\
Precinct Segregation (Dissimilarity Index) & 0.595 & 0.153 & 2010 Census, block- \\
& & & level calculation \\
Precinct \% Voted Republican in 2008 & 0.557 & 0.289 & MS SOS \\
Precinct \% White VAP that is Female & 0.513 & 0.056 & 2010 Census \\
\hline \hline
\end{tabular}

$n=1,733$ precincts for which all data were available ( 88 percent of statewide precincts)

*Dependent variable in Figure 2

population in precinct $i$, and similarly for NonWhite N $_{j}$ and NonWhite $_{T}$. D ranges in value from 0 to 1 , where higher values indicate more segregation (Massey and Denton, 1988).

In addition to these focal predictors, we control for (1) the percentage of the white VAP that is female, (2) precinct-level support for the Republican presidential candidate in the immediately preceding presidential election, and (3) unobserved county-level fixed effects through dummy variables. Concerning the former, there is reason to believe that Initiative 27 might negatively affect women more than men. The reason for this expectation is that, due to marriage-related name changes, more women are likely to possess photo IDs that contain outdated nominal information relative to men; and outdated identification is invalid for voting purposes (Drum, 2011). Hence, women might be inclined to oppose the ballot measure not because of, for instance, social contact with minorities, but because they (women) could also be negatively affected by the voter ID law. It is therefore important to control for the gender of the white VAP to reduce the probability that gender-based white opposition to Initiative 27 is mistaken for opposition due to the social contact effect described above. Second, we follow instructive studies in modeling precinct-level "political ideology" by controlling for support for the Republican candidate in the most recent (i.e., 2008) presidential election (Tolbert and Grummel, 2003; Karahan and Shughart, 2004; Roch and Rushton, 2008; Orey et al., 2011). To the extent that Republican voters tend to be relatively politically conservative and the voter ID issue is associated with conservative politics (Alth, 2008), we expect that white support for voter ID and Republicanism will exhibit a direct relationship. Finally, we include binary variables to control for the unobserved, stable attributes of each county. Given our choice of analytical unit (voting precinct), data for controls related to white socioeconomic status are unavailable to use as predictors [see the discussion in Liu (2001)]. Namely, whereas factors such as the educational attainment, poverty status, and income levels of an area's white population have been found to 
be statistically significant predictors of white support for nonminority-preferred alternatives at the county scale (e.g., Orey et al., 2011), such data are not collected for disaggregated votingprecinct geographies. Moreover, while it is possible to aggregate Census block-level data to voting precincts as discussed above, it is not possible to do this for the lower-resolution Census block-group geography without interpolating. This limits our analysis, as the block group is the smallest Census unit for which socioeconomic data are reported; and, due to the estimated nature of our dependent variable, we are reluctant to include interpolated variables as predictors in the analysis. That being said, we assume that the inclusion of county binary variables will mitigate this data availability issue to some degree. Further, we do control for more of the politicalgeographic and demographic attributes of our study region relative to comparable precinct-level research (e.g., Liu, 2001).

\section{METHODS AND RESULTS}

Both King (1997) and racial vote-polarization scholars who use King's EI method to construct their dependent variables recommend estimating models of white support for nonminority-preferred alternatives using weighted least squares (WLS) regression. The weighting vector used in the approach contains the inverse standard errors of the EI-derived point estimates for the dependent variable (Tolbert and Hero, 2001; Tolbert and Grummel, 2003; Roch and Rushton, 2008). ${ }^{6}$ We follow these recommendations to study variation in white support for the Mississippi voter ID policy. But we apply a few additional specifications to evaluate the conceptual model in Figure 2. Crucially, the proposed relationship requires the creation of two multiplicative interaction terms, as shown in Muller et al. (2005). To both mitigate multicollinearity issues ${ }^{7}$ and enhance coefficient interpretability, all variables that are involved in multiplicative interactions are mean-centered prior to regression estimation (Jaccard and Turrisi, 2003; Muller et al., 2005; Orey et al., 2011).

First, the relative size of the minority population is multiplicatively interacted with the degree of precinct urbanization to create a predictor to capture the moderated relationship between minority population and white voting behavior extolled by social contact proponents (Voss, 2000; Voss and Miller, 2001) and adopted by racial threat proponents (Orey et al., 2011). However, if the moderated-mediated relationship that we posit (Fig. 2) exists, then according to Muller et al. (2005) this interaction term should also be a statistically significant predictor of the proposed mediator variable: segregation (refer to Fig. 2) Second, precinct segregation is multiplied by precinct urbanization. To demonstrate that the relationship in Figure 2 holds, one of two patterns should occur when both of these interactions, and their constituent parts, are evaluated within the WLS regression models: either, (1) the urbanization and minority population interaction is a significant predictor of segregation, and segregation is a significant predictor of white support for the voter ID policy; or (2) minority population size is a significant predictor of segregation, and the segregation and urbanization interaction is a significant predictor of white support for the voter ID policy (Muller et al., 2005). According to our logic above - namely, that urbanization moderates the relationship between minority population and segregation and that minority population size affects white voting behavior indirectly through its

\footnotetext{
${ }^{6}$ This methodological strategy is "suggested by King (1997)" in his book on the EI method (Roch and Rushdon, 2008, p. 626), as it is intended to "give more weight to the more reliable estimates" of the dependent variable (Tolbert and Grummel, 2003, p. 191).

${ }^{7}$ Multicollinearity inevitably arises when two predictors are interacted and included in a model simultaneously with those predictors.
}

(C) Southern Regional Science Association 2015. 
effect on residential segregation (see Figure 2) - the first of these cases is expected to manifest in analyses of racially polarized voting outcomes.

The results from estimating WLS models that test for moderation, and moderatedmediation, are included in columns two and three of Table 3, respectively. These models are

Table 3: Output, Weighted Least Squares with County Dummies

\begin{tabular}{|c|c|c|c|}
\hline Variable & $\begin{array}{c}\text { Test for } \\
\text { Moderation } \\
\mathrm{dv}=\text { White Support } \\
\text { for Voter ID }\end{array}$ & $\begin{array}{l}\text { Test for Moderation } \\
\text { in the Mediator } \\
d v=\text { Segregation }\end{array}$ & $\begin{array}{l}\text { Final Moderated }^{\mathrm{F}} \\
\text { Mediation Model }^{\mathrm{a}} \\
\mathrm{dv}=\text { White Support } \\
\text { for Voter ID }\end{array}$ \\
\hline$\%$ Minority Population ${ }^{\dagger}$ & $\begin{array}{c}0.055^{* * *} \\
(0.014)\end{array}$ & $\begin{array}{l}-0.031 \\
(0.033)\end{array}$ & $\begin{array}{c}0.052 * * * \\
(0.014)\end{array}$ \\
\hline$\%$ Urbanized $^{\dagger}$ & $\begin{array}{c}0.002 \\
(0.007)\end{array}$ & $\begin{array}{c}-0.073 * * * \\
(0.016)\end{array}$ & $\begin{array}{c}0.003 \\
(0.008)\end{array}$ \\
\hline $\begin{array}{l}\% \text { Minority Population }{ }^{\dagger} \mathrm{x} \\
\% \text { Urbanized }^{\dagger}\end{array}$ & $\begin{array}{c}-0.066^{* * *} \\
(0.019)\end{array}$ & $\begin{array}{c}0.216^{* * *} \\
(0.045)\end{array}$ & $\begin{array}{c}-0.062 * * * \\
(0.020)\end{array}$ \\
\hline Segregation $^{\dagger}$ & -- & -- & $\begin{array}{c}-0.039 * * * \\
(0.012)\end{array}$ \\
\hline $\begin{array}{l}\text { Segregation }{ }^{\dagger} \mathrm{x} \\
\% \text { Urbanized }^{\dagger}\end{array}$ & -- & -- & $\begin{array}{c}0.053 \\
(0.034)\end{array}$ \\
\hline $\begin{array}{l}\text { White Voting Age } \\
\text { Population \% Female }\end{array}$ & $\begin{array}{c}0.142 * * * \\
(0.047)\end{array}$ & $\begin{array}{l}0.218^{* *} \\
(0.109)\end{array}$ & $\begin{array}{c}0.151^{* * * *} \\
(0.047)\end{array}$ \\
\hline $\begin{array}{l}\text { \% Voted Republican in } \\
2008 \text { Presidential Election }\end{array}$ & $\begin{array}{c}0.106^{* * * *} \\
(0.012)\end{array}$ & $\begin{array}{l}-0.007 \\
(0.028)\end{array}$ & $\begin{array}{c}0.105^{* * * *} \\
(0.012)\end{array}$ \\
\hline County Dummies & $\checkmark$ & $\checkmark$ & $\checkmark$ \\
\hline Intercept & $0.715 * * *$ & $-0.161 * *$ & $0.706 * * *$ \\
\hline $\begin{array}{l}\mathrm{R}^{2} \\
\mathrm{n} \text { (\# of precincts) }\end{array}$ & $\begin{array}{c}0.48 \\
1,733 \\
\end{array}$ & $\begin{array}{r}0.42 \\
1,733 \\
\end{array}$ & $\begin{array}{c}0.49 \\
1,733 \\
\end{array}$ \\
\hline $\begin{array}{l}* * \mathrm{p}<0.05 * * * \mathrm{p}<0.01 ; \mathrm{HAC} \text { stan } \\
\text { from this model were tested for } \\
\text { band to ensure that all precincts } \\
\text { at a } 99 \text { percent level of confiden } \\
\text { its magnitude was quite small at } \\
-10 \text { (complete disnersion) to }+1\end{array}$ & $\begin{array}{l}\mathrm{d} \text { errors in parentheses } \\
\text { tial autocorrelation usi } \\
\text { lat least one spatial ne } \\
\text { (i.e., we fail to reject th } \\
2 \text {. To add context to th }\end{array}$ & $\begin{array}{l}\text { Mean-centered; } \mathrm{dv}=\text { depend } \\
\text { the global Moran's I statistic } \\
\text { bor. The global statistic was } \\
\text { ull hypothesis of spatially ur } \\
\text { result, consider that the Mor }\end{array}$ & $\begin{array}{l}\text { variable; }{ }^{\text {a }} \text { The residuals } \\
\text { d a threshold distance } \\
\text { statistically significant } \\
\text { rrelated residuals), and } \\
\text { I ranges in value from } \\
\text { andomness. }\end{array}$ \\
\hline
\end{tabular}

(C) Southern Regional Science Association 2015. 
estimated and presented only to illustrate that key empirical conditions for moderatedmediation, ${ }^{8}$ as hypothesized in Figure 2, do indeed hold. Our main interest is in the results from estimating the final (full) model, which are shown in the fourth column of Table 3 . Together, the observations that the urbanization and minority population interaction term is statistically significant in all three models and that segregation is statistically significant in the full model, support the hypothesis of a moderated-mediated relationship [see Muller et al. (2005) for a detailed discussion]. In a quantitative sense, the results presented in the final column of Table 3 imply that the residual direct effect of minority population size on white support for Initiative 27 is moderated, once segregation is controlled (Muller et al., 2005). Stated more practically, the interaction of urbanization and minority population is a statistically significant predictor of segregation, and segregation is a statistically significant predictor of white support for Initiative 27. Together they suggest that part of the effect that the minority population has on white support comes from the direct effect that the former has on the degree to which racial groups are residentially segregated within voting precincts. Its magnitude depends on the extent to which a precinct is urbanized. This idea is clarified and expanded upon shortly.

Note that because the variables involved in multiplicative interactions are mean-centered, the regression coefficients on these predictors quantify conditional, not general, partial relationships (Jaccard and Turrisi, 2003). It is therefore useful to re-estimate the full model at different levels of urbanization to understand how the rural-urban continuum moderates the relationship between minority population size and white support for voter ID, controlling for segregation. We follow the example in Jaccard and Turrisi (2003) by re-centering urbanization at "low," "medium," and "high" levels, which correspond to values of one standard deviation below the mean, at the mean, and one standard deviation above the mean, respectively. Reestimating the model with these values only alters the (conditional) coefficient and standard error estimates for minority population size and segregation - the model diagnostics and unconditional effects will remain invariant to the transformations (Jaccard and Turrisi, 2003). That being said, the model is reevaluated for the three aforementioned levels of urbanization. The resulting changes to the minority population coefficient-standard error pairs are given in Table 4, along with new intercepts computed for each level of urbanization (see Jaccard and Turrisi, 2003).

The intercepts and coefficients from Table 4 can be used in conjunction with the partial effects estimated for the full model in Table 3 to plot the relationship between the dependent

\footnotetext{
${ }^{8}$ These conditions are only partially detailed in the preceding paragraph of the text. Following Muller et al. (2005), the full set of empirical conditions that should be met, according to the conceptual model, includes: (1) in a regression of white support for voter ID (dependent variable) on only minority population size and the control variables, the effect of minority population size must be statistically significant; (2) minority population size must be statistically significant in a regression of segregation (proposed mediator) on minority population size; (3) the mediator must have a statistically significant effect on the dependent variable in a model featuring minority population size (but not the interaction of these variables); (4) the effect of minority population size described in condition (3) must be smaller than the variable's effect described in condition (1); (5) in a regression of the dependent variable on (a) minority population size, (b) urbanization (proposed moderator), and (c) the interaction of (a) and (b), (c) must be significant; (6) in a regression of the mediator on the same set of variables discussed in condition (5), the interaction of minority population size and the moderator should be statistically significant; (7) if the above conditions hold, then in the full moderated-mediated model, the effect of minority population size, the moderated effect of minority population size, and the effect of the mediator should all be statistically significant. Each of these conditions were evaluated and found to hold. Conditions (1)-(4) were evaluated in models that are not presented in Table 3 to make the exposition more succinct. Conditions (5)-(7) are established by the three models described in Table 3, where the final column of Table 3 is the full model that corresponds to Figure 2 (Muller et al., 2005; also see Jaccard and Turrisi, 2003; Jaccard and Jacoby, 2010). Conditions (5)-(7) are described in more practical terms in the preceding paragraph of the text.
}

(C) Southern Regional Science Association 2015. 
Table 4: Effect of Urbanization on White Voter ID Support

\begin{tabular}{lcc}
\hline $\begin{array}{l}\text { Level of } \\
\text { Urbanization }\end{array}$ & Intercept & $\begin{array}{c}\text { \% Minority Population } \\
\text { Coefficient (std. err.) }\end{array}$ \\
\hline Low & 0.732 & $0.077^{* * *}(0.018)$ \\
Mean & 0.706 & $0.052^{* * *}(0.014)$ \\
High & 0.681 & $0.026^{*}(0.016)$ \\
\hline Note: ${ }^{*} \mathrm{p}<0.10,{ }^{* *} \mathrm{p}<0.05$, and ${ }^{* * *} \mathrm{p}<0.01$. &
\end{tabular}

variable (white support for the voter ID policy) and minority population size at the specified low, medium, and high levels of urbanization (Figure 3). While Figure 3 shows that this relationship is generally positive, it is also clear that urbanization significantly mitigates this tendencycontrolling for segregation. Comparing the solid line in Figure 3 to its counterparts reveals that white support for Initiative 27 is significantly lower in highly urbanized precincts relative to precincts with low or medium urbanization levels. This is true for all sizes of the minority population, holding segregation constant. Moreover, at high levels of urbanization, the positive relationship between white support for voter ID and minority population size is no longer significant at either a 99 percent or 95 percent level of confidence (Table 4). In short, the effects of minority population size on white "hostility," via the mediating effects of segregation, support the racial threat hypothesis in general; but the moderating influence of urbanization counteracts these forces in highly urbanized settings, thus supporting the social contact hypothesis. Consistent with prior research (Orey, 1998, 2001; Rocha and Espino, 2009), whether one or the other of these hypotheses is better suited for explaining Initiative 27 voting patterns is conditional on sociospatial organization.

Returning to the notion that minority population size influences white support for Initiative 27 both directly and indirectly through the impact it has on precinct-level racial segregation, we compute these two sets of effects for the low, medium, and high levels of urbanization just described using the relevant coefficients in the third and fourth columns of Table 3 [see Muller et al. (2005) for a step-by-step illustration of this process]. The results from these calculations are presented in Table 5. It is evident from the table that increases to the minority population size in highly urbanized precincts have offsetting influences on white hostility, while the opposite holds for less urbanized areas. ${ }^{9}$ More explicitly, increasing minority population size tends to decrease precinct segregation (Table 3, column 3), and through this effect the former is associated with less white support for the voter ID policy in highly urbanized precincts (refer to the first entry in the second column of Table 4). The indirect effects are fairly small for all levels of precinct urbanization. Still, their signs and relative magnitudes provide evidence that the racial threat and social contact hypotheses are not mutually exclusive and, instead, operate in the differential geography nested within a single study area.

Prior to moving forward, it is worthwhile to draw attention to the estimated relationships between the dependent and control variables in the models (Table 3). As anticipated, conservative political ideology-represented here by precinct support for the Republican candidate in the immediately preceding (2008) presidential election (e.g., Roch and Rushton, 2008; Orey et al., 2011) - predicts white support for the voter ID policy in a positive and statistically significant manner. This finding is not so unsurprising as it supports existing claims

\footnotetext{
${ }^{9}$ Note that the "direct effects" simply correspond to the estimated minority population coefficients from Table 4.
}

(C) Southern Regional Science Association 2015. 
Table 5: Indirect and Direct Effects of Minority Population Size on White Support for Voter ID*

\begin{tabular}{lcc}
\hline \hline Urbanization & $\begin{array}{c}\text { Total Indirect Effects of Minority } \\
\text { Population on White Support for } \\
\text { Initiative 27, via Segregation }\end{array}$ & $\begin{array}{c}\text { Residual Direct Effects of Minority } \\
\text { Population on White Support for } \\
\text { Initiative 27 }\end{array}$ \\
\hline High & -0.001 & 0.026 \\
Medium & 0.001 & 0.052 \\
Low & 0.007 & 0.077 \\
\hline \hline
\end{tabular}

*See Muller et al. (2005) for detailed information on how to calculate these effects from the coefficients in Table 3 .

\section{Figure 3: White Support for Initiative 27 v. Mean-Centered Minority Population Size for Low, High, and Medium Levels of Urbanization}

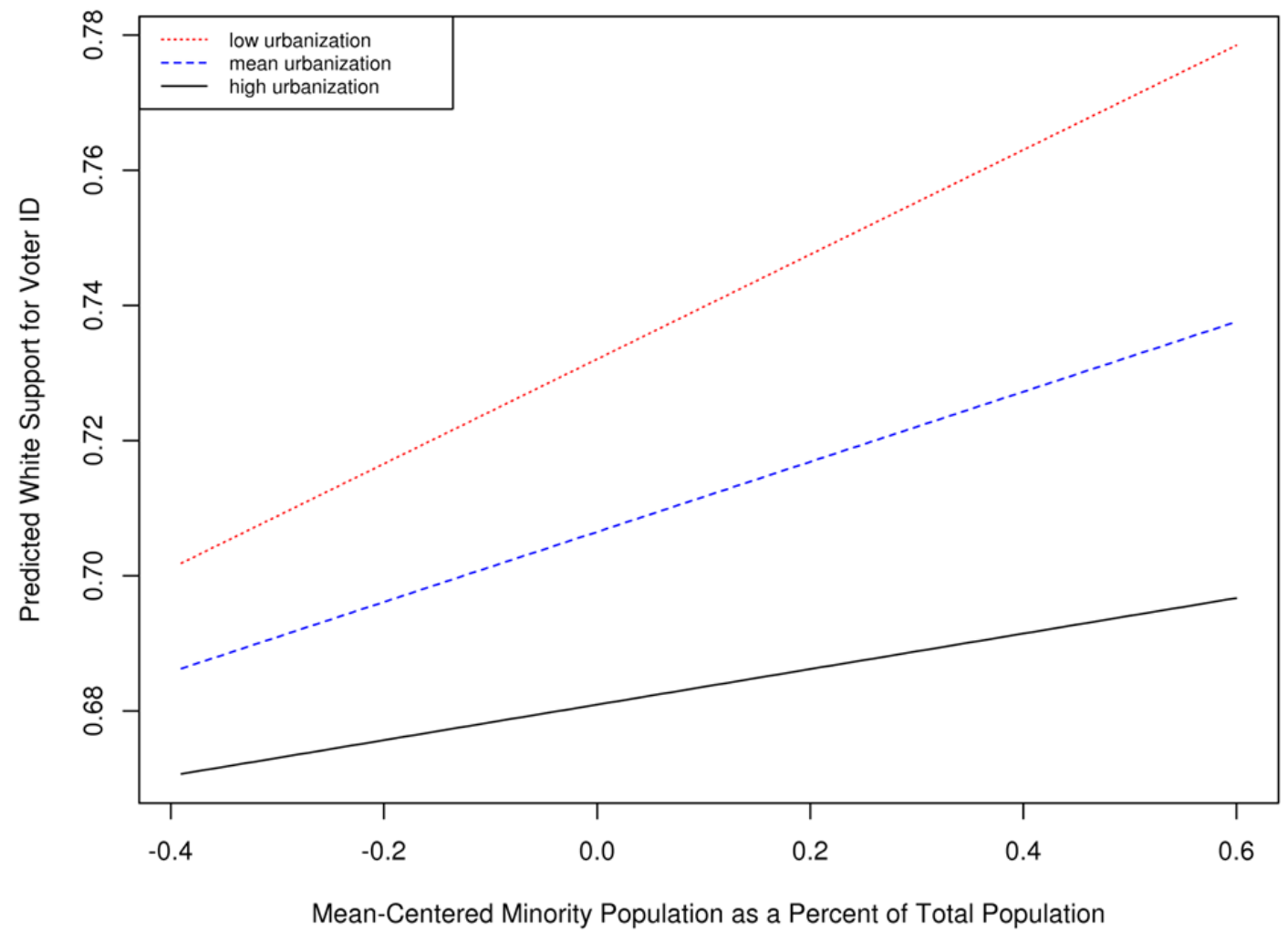

of an association between Republicanism and the desire to impose stricter voting requirements on the electorate (Hood and Bullock, 2008; Alth, 2008). In contrast, the estimated relationship between white female VAP and white support for Initiative 27 stands in stark opposition to our initial expectations. More precisely, while as anticipated the female component of white VAP is related to our dependent variable in a statistically significant manner ceteris paribus, an increase to the number of voting-age-eligible white females is associated with more support for the voter ID policy among whites, rather than less as was expected. We do not have an immediate explanation for this finding. But recent research on southern regional politics reveals that southern women are beginning to vote more conservatively on some issues than southern men (Rice and Coates, 1995; Cooper and Knotts, 2006). Our unexpected result is perhaps a reflection of this emerging pattern. 


\section{CONCLUSIONS}

In this piece, we expand on Key's (1949) classic observations about the relationship between minority population size and white political support for nonminority preferred alternatives in the U.S. by introducing critical spatial attributes into the conceptual model of racially polarized voting outcomes. Whereas prior research (Orey, 1998, 2001; Voss 2000; Voss and Miller, 2001; Tolbert and Grummel, 2003; Orey et al., 2011) has built a solid empirical foundation that asserts this relationship is moderated by the urban-rural character of a given region, the literature has been comparatively inattentive to the influences of residential racial segregation on the phenomenon of interest. The limited work that does investigate these influences (Roch and Rushton, 2008; Rocha and Espino, 2009, 2010) also dismisses the established moderating role of an urban-rural geographic context. We therefore propose a comparatively comprehensive model of racially polarized voting outcomes that accounts for the intervening effects of both regional urbanization and segregation. Explicitly, we advance a moderated-mediated model of white support for nonminority-preferred alternatives. We then test it using data for a recent racially polarized voter ID referendum election in the southern U.S. state of Mississippi.

The motivation for this analysis lies in the heretofore contradictory results produced by similar quantitative investigations into instances of racial vote polarization (e.g., Voss and Miller, 2001; Orey et al., 2011). Where racial threat proponents (e.g., Orey et al., 2011) find that (controlling for urbanization) larger minority shares of regional population raise white opposition to minority-preferred political alternatives, other researchers (Voss, 1996, 2000; Voss and Miller, 2001) reach the opposite conclusion while using comparable assumptions, methods, and geographic scopes. Framed in this debate, we find that racially polarized precinct-level election results for Mississippi's 2011 voter ID referendum follow neither of these patterns in an absolute sense. Rather, the applicability of either the racial threat or the competing social contact hypothesis to our case is conditioned on spatial context. Adhering to the logical constructs of our conceptual model, minority population size affects white support for the Mississippi voter ID policy - both directly and indirectly through its generally negative effect on residential segregation. Moreover, these influences hinge on the degree to which a given voting precinct is urbanized.

Consistent with findings from related studies (Orey, 1998, 2001; Voss, 2000; Voss and Miller, 2001), we observe that urbanization counteracts prevailing racial threat tendencies in the Mississippi voter ID referendum. That is, whites residing in highly urbanized precincts are significantly less likely than whites living in relatively non-urbanized territories to exhibit racially "hostile" voting behavior. The findings suggest that this outcome is due in part to a negative indirect influence that large urban minority populations exert on white support for voter ID, via their (negative) effect on local patterns of residential segregation. By contrast, the direct (positive) impact that minority population size has on white support for Initiative 27 augments itself in non-urbanized precincts, and it appears to do so via positive mediating effects through segregation. Thus, we observe patterns that reflect the co-existence in the same election and region of social contact along with clear indicators of racial threat. The former occupy spaces that are more urbanized, and contrarily the latter. In light of evidence from recent studies of intergroup political relations (Oliver and Wong, 2003; Rocha and Espino, 2009, 2010), it is reasonable to hypothesize that these patterns likely persist more generally throughout the geography of the U.S. South and potentially beyond.

(C) Southern Regional Science Association 2015. 
Overall, we conclude that introducing additional spatial considerations into the racial threat/social-contact discourse is crucial to resolving the apparent contradiction between the two hypotheses. By incorporating residential racial segregation as a mediator into the conceptual model of racial vote polarization, we gain an increase in the model's explanatory power over the established moderated relationship in other contemporary literature (Orey, 1998, 2001; Voss and Miller, 2001; Tolbert and Grummel, 2003; Orey et al., 2011). ${ }^{10}$ Even though these gains may be marginal in size, the statistically significant evidence uncovered via the moderated-mediation effect represents a step forward in understanding the multiple roles of multiple geographies in polarized voting outcomes. To that end, we encourage future research, especially from interdisciplinary regional scientists, aimed at identifying other spatial relationships that are not presently featured in polarization studies. Additionally, in the context of the data limitations discussed in Section 5.2, a valuable extension to this line of research will be to incorporate more explanatory variables - especially socioeconomic indicators-into relatively high resolution (e.g., precinct-level) models of racial polarization. This objective can plausibly be accomplished through areal interpolation and leveraging advanced geographic information systems software. Complementing it with ecological analyses (such as the one presented hereinbefore) via highquality survey data and survey-based studies would help as well. Such work will undoubtedly improve our understanding of the contexts and residential environments in which white political opposition to minority preferred alternatives is or is not cultivated.

\section{REFERENCES}

De Alth, Shelley. (2008) "ID at the Polls: Assessing the Impact of Recent State Voter ID Laws on Voter Turnout," Harvard Law \& Policy Review, 3, 185-202.

Barreto, Matt A., Stephen A. Nuño, and Gabriel R. Sanchez. (2009) "The Disproportionate Impact of Voter ID Requirements on the Electorate - New Evidence from Indiana," PS: Politics and Political Science, 42, 111-116.

Baybeck, Brady. (2006) "Sorting out the Competing Effects of Racial Context," The Journal of Politics, 68, 386-396.

Beachler, Donald W. (2001) "All About Race? Electoral Politics in Mississippi," Politics \& Policy, 29, 585-599.

Berry, Deborah B. (2011) "Debate Heats up over Voter ID Laws," USA Today, 10 November 2011. Available online in August 2015 at http://usatoday30.usatoday.com/news/washington/story/2011-11-10/voter-identificationlaws/51159106/1.

Blalock, Hubert M. (1967). Toward a Theory of Minority-Group Relations. John Wiley \& Sons, Inc.: New York.

Carsey, Thomas M. (1995) "The Contextual Effects of Race on White Voter Behavior: The 1989 New York City Mayoral Election,” Journal of Politics, 57, 221-228.

Cohen, Jon and Rosalind S. Helderman. (2012) "Poll Shows Widening Racial Gap in Presidential Contest," Washington Post, 25 October. Available online in August 2015 at

${ }^{10}$ As evidenced by comparing the $\mathrm{R}^{2}$ values in the second and final columns of Table 3 .

(C) Southern Regional Science Association 2015. 
http://www.washingtonpost.com/politics/decision2012/poll-shows-widening-racial-gapin-presidential-contest/2012/10/25/9d5be0d4-1ed1-11e2-9cd5-b55c38388962_story.html.

Cooper, Christopher A. and H. Gibbs Knotts. (2006) "Region, Race, and Support for the South Carolina Confederate Flag," Social Science Quarterly, 87, 142-154.

Davidson, Chandler. (2009) "The Historical Context of Voter Photo-ID Laws," Political Science and Politics, 42, 93-96.

Donovan, Todd. (2010) "Obama and the White Vote," Political Research Quarterly, 63, 863-874.

Drum, Kevin. (2011) “Do Voter ID Laws Target Women?," Mother Jones, 28 July. Available at http://www.motherjones.com/print/124837.

Forbes, H. D. (1997) Ethnic Conflict: Commerce, Culture, and the Contact Hypothesis. Yale University Press: New Haven, CT.

Fund, John and Hans von Spakovsky. (2013) Who's Counting?: How Fraudsters and Bureaucrats Put Your Vote at Risk. Encounter Books: Jackson, TN.

Giles, Michael W. (1977) "Percent Black and Racial Hostility: An Old Assumption Reexamined," Social Science Quarterly, 58, 417-417.

Giles, Michael W. and Melanie A. Buckner. (1993) "David Duke and the Black Threat: An Old Hypothesis Revisited," Journal of Politics, 55, 702-713.

Hood, M. V., III and Charles S. Bullock, III. (2008) "Worth a Thousand Words? An Analysis of Georgia's Voter Identification Statute," American Politics Research, 36, 555-579.

Hood, M. V., III and Irwin L. Morris. (2000) "Brother, Can You Spare a Dime? Racial/Ethnic Context and the White Vote on Proposition 187," Social Science Quarterly, 81, 194-206.

Huckfeldt, Robert and John Sprague. (1993) "Citizens, Contexts, and Politics," in Ada W. Finifter (ed.), Political Science: The State of the Discipline II. American Political Science Association: Washington, DC, pp. 281-303.

Jaccard, James and Jacob Jacoby. (2010) Theory Construction and Model-building Skills. The Guilford Press: New York, NY.

Jaccard, James and Robert Turrisi. (2003) Interaction Effects in Multiple Regression, $2^{\text {nd }}$ edition. Sage: Thousand Oaks, CA.

Karahan, Gokhan R. and William F. Shughart. (2004) "Under Two Flags: Symbolic Voting in the State of Mississippi," Public Choice, 118, 105-124.

Key, V.O., Jr. (1949) Southern Politics in State and Nation. University of Tennessee Press: Knoxville, TN.

King, Gary. (1997) A Solution to the Ecological Inference Problem. Princeton University Press: Princeton, NJ.

Liu, Baodong. (2001) "The Positive Effect of Black Density on White Crossover Voting: Reconsidering Social Interaction Theory," Social Science Quarterly, 82, 602-615. 
Lublin, David and D. Stephen Voss. (2002) "Context and Francophone Support for the Sovereignty of Quebec: An Ecological Analysis," Canadian Journal of Political Science, $35,75-101$.

Massey, Douglas S. and Nancy A. Denton. 1988. "The Dimensions of Residential Segregation," Social Forces, 67, 281-315.

McCrary, Peyton. (1990) "Racially Polarized Voting in the South: Quantitative Evidence from the Courtroom," Social Science History, 14, 507-531.

Minnite, Lorraine C. (2007) The Politics of Voter Fraud. ProjectVote: Washington, DC. Available online in August 2015 at

http://projectvote.org/images/publications/Policy\%20Reports\%20and\%20Guides/Politics _of_Voter_Fraud_Final.pdf.

Muller, Dominique, Charles M. Judd, and Vincent Y. Yzerbyt. (2005) "When Moderation is Mediated and Mediation is Moderated," Journal of Personality and Social Psychology, $89,852-863$.

NAACP. (2011) Defending Democracy: Confronting Modern Barriers to Voting Rights in America. NAACP Legal Defense Fund: Washington, DC. Available online in August 2015 at http://naacp.3cdn.net/67065c25be9ae43367_mlbrsy48b.pdf.

Oliver, J. Eric and Tali Mendelberg. (2000) "Reconsidering the Environmental Determinants of White Racial Attitudes," American Journal of Political Science, 44, 574-589.

Oliver, J. Eric and Janelle Wong. (2003) "Intergroup Prejudice in Multiethnic Settings," American Journal of Political Science, 47, 567-582.

Orey, Byron D. (2001) "A New Racial Threat in the New South? (A Conditional) Yes," The American Review of Politics, 22, 233-255.

. (1998) "The Race Race in Black and White: The 1995 Louisiana Gubernatorial Election," Southeastern Political Review, 26, 909-922.

Orey, Byron D., L. Marvin Overby, Peter K. Hatemi, and Baodong Liu. (2011) "White Support for Racial Referenda in the Deep South," Politics and Policy, 39, 539-558.

Pew Research Center. (2012) Broad Support for Photo ID Voting Requirements. Pew Research Center for the People \& the Press: Washington, DC. Available online in August 2015 at http://www.people-press.org/files/legacy-pdf/10-11-12\%20Voter\%20ID\%20release.pdf

Rice, Tom W. and Diane L. Coates. (1995) "Gender Role Attitudes in the Southern United States," Gender and Society, 9, 744-756.

Roch, Christine H. and Michael Rushton. (2008) "Racial Context and Voting over Taxes: Evidence from a Referendum in Alabama," Public Finance Review, 36, 614-634.

Rocha, Rene R., and Rodolfo Espino. (2010) "Segregation, Immigration, and Latino Participation in Ethnic Politics," American Politics Research, 38, 614-635.

. (2009) "Racial Threat, Residential Segregation, and the Policy Attitudes of Whites," Political Research Quarterly, 62, 415-426.

(C) Southern Regional Science Association 2015. 
Shaffer, Stephen D., Patrick R. Cotter, and Ronnie B. Tucker. (2000) "Racism or Conservativism: Explaining the Rising Republicanism in the Deep South," Southeastern Political Review, 28, 133-148.

Sigelman, Lee and Susan Welch. (1993) "The Contact Hypothesis Revisited: Black-White Interaction and Positive Racial Attitudes," Social Forces, 71, 781-795.

Stein, Robert M., Stephanie S. Post, and Allison L. Rinden. (2000) "Reconciling Context and Contact Effects on Racial Attitudes," Political Research Quarterly, 53, 285-303.

Texas v. Holder. (2012) 1:12-cv-00128 (RMC-DST-RLW), (D.D.C. Aug. 30, 2012).

Tolbert, Caroline J. and Rodney Hero. (2001) "Facing Diversity: Racial/Ethnic Context and Social Policy Change," Political Research Quarterly, 54, 571-604.

Tolbert, Caroline J. and John A. Grummel. (2003) "Revisiting the Racial Threat Hypothesis: White Voter Support for California's Proposition 209," State Politics \& Policy Quarterly, 3, 183-202.

Voss, D. Stephen. (2000) Familiarity Doesn't Breed Contempt: The New Geography of Racial Politics, unpublished Ph.D. dissertation, Harvard University.

. (1996) "Beyond Racial Threat: Failure of an Old Hypothesis in the New South," The Journal of Politics, 58, 1156-1170.

Voss, D. Stephen and Penny Miller. (2001) "Following a False Trail: The Hunt for White Backlash in Kentucky's 1996 Desegregation Vote," State Politics \& Policy Quarterly, 1, $62-80$.

Webster, Gerald R. and Nicholas Quinton. (2010) "The Electoral Geographies of Two Segregationist ('Jim Crow') Referenda in Alabama," Political Geography, 29, 370-380.

(C) Southern Regional Science Association 2015. 